\title{
Colorimetric Sensor for Determination of Allura Red (E129) in Present of Prussian Blue
}

\author{
Kobun Rovina* \\ Faculty of Food Science, University Malaysia Sabah, Malaysia \\ *Corresponding author: Kobun Rovina, Faculty of Food Science and Nutrition Jalan, UMS 88400 Kota Kinabalu Sabah, University Malaysia Sabah, \\ Malaysia
}

Submission: August 03, 2018; Published: September 26, 2018

\begin{abstract}
Allura Red AC (E 129) belongs to synthetic mono azo dye group with strong vivid colors and widely used as food colorants to make them visually aesthetic. Allura Red have been claimed toxic, carcinogens and contributors to health problems for human when excessively consume. Hence, there is needed a simple, faster and effective method for the analysis of Allura Red in food products. Herein, colorimetric sensor for rapid and simple detection of Allura Red was developed by interaction of Potassium Hexacyanoferrate (III) and Iron (III) Chloride hexahydrate as Prussian blue. Under optimal conditions ( $\mathrm{pH}: 1.0,26 \mathrm{oC}$ and 2 minutes), the proposed colorimetric sensor was found a wide linear Allura Red concentration range from 20 to $2 \mathrm{ppm}$, with a limit of detection $(3.3 \sigma / \mathrm{s})$ and limit of quantification $(10 \sigma / \mathrm{s})$ calculated are $0.0244 \mathrm{ppm}$ and $0.0738 \mathrm{ppm}$, respectively. Finally, the proposed sensor method was successfully applied to determine Allura Red in different food products with satisfactory results.
\end{abstract}

\section{Introduction}

Color is one of important features as food colorant which plays an important role in the food industries. Nowadays, food dyes have been used to improve the appearance of foods to increase quality, taste and flavor of foodstuffs [1]. Any dye, pigment, or other substance that is derived from either natural resource (vegetable, animal and mineral) or synthetic that is used in application for food, drug or human body is called color additive [2]. Generally, there are two types of food dyes including natural and synthetic dyes. Natural food colorants are obtained from various food material or other natural materials. Furthermore, synthetic food colorants can be synthesis using artificial synthesis method usually by coal tar from aniline dyes as raw material [3]. Synthetic food colorants are widely used in food industry because of the low cost, interactive color and strong tinting ability. Food colorants also are used to enhance the aesthetic appeal of processed food. These food colorants are considered important because they can give colors to many food products that are naturally colorless [4].

Allura Red AC (E129) are reported most commonly used in Malaysia for food processing. Allura Red consists essentially of 6-hydroxy-5-(2-methoxy-5-methyl-4-sulfophenyl) azo-2naphtalenesulfonic acid sodium salt (or disodium 2-hydroxy1-(2-methoxy-5-methyl-4sufonato-phenylazo)-naphthalene-6sulfonate) shown in Figure 1. It can be synthesized by coupling diazotized 5-amino-4-4methoxy-2-toluenesulfonic acid with 6-hydroxy-2-naphthalenesulfonic acid [4]. Allura Red also known as Food Red No. 40 and Food, Drug and Cosmetic (FD\&C) Red No. 40. It is water soluble, insoluble in ethanol, dark red in color and it can be in the form of powder or granules. Allura Red most commonly used in soft drinks, children's medications, and cotton candy [5].

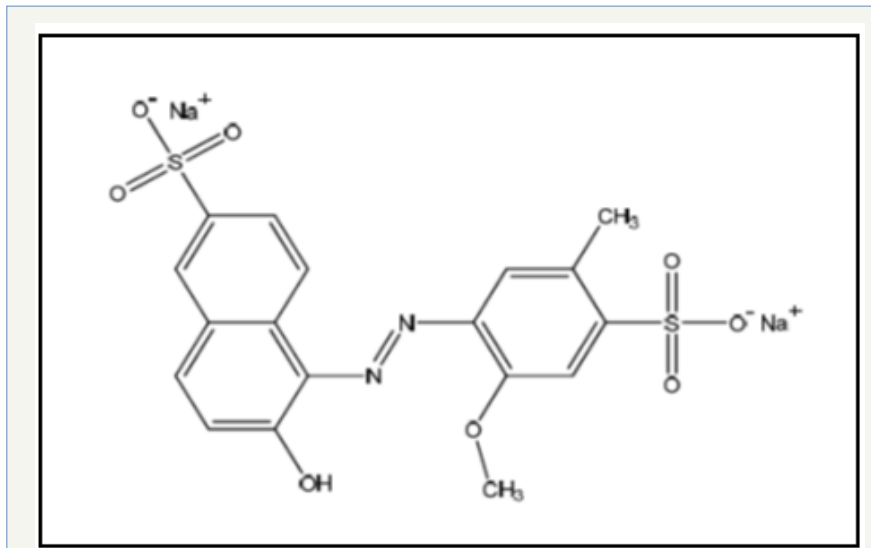

Figure 1: Structure of Allura Red AC.

Excess consumption of food coloring must be controlled because its presence and contact with some kinds of drugs including aspirin, benzoic acid and other analgesics in human body. Several health problems have been reported caused by Allura Red including intoxications, allergic, asthmatic illness and death cases [1]. Recently, there are regulations that have been created in order to give guidelines to consumer about the consumption of these food dyes. In EU and US Regulation, there are acceptable daily intake, utilization and limits of food coloring in foods for Allura Red is less than $7 \mathrm{mg} / \mathrm{kg}$. Due to the concern of consumption of food with synthetic food dyes, there is several analytical methods has been develop including chromatography, spectrophotometry, mass spectrometry, differential pulse polarography, capillary electrophoresis and various combinations of these techniques [6]. These methods have high sensitivity and selectivity, however; many of them are time-consuming and labor-intensive due to the complex pretreatment, requires expensive instrumentation and high cost of 
personnel and are not readily adaptable to on-site detection [7].

Hence, there is increasing demand for a new method that is much easier, low cost and rapid, high sensitivity and selectivity for determination of Allura Red in foodstuff. The main objective of this study was to detect Allura Red through the interaction of Prussian blue. The proposed method was successfully applied in food products in local market with satisfactory results.

\section{Experimental}

\section{Reagent and chemicals}

Allura Red AC, Iron (III) Chloride Hexahydrate and Potassium Hexacyanoferrate (III) were purchased from Sigma Aldrich (USA). Prussian blue was prepared by dissolving Iron (III) Chloride Hexahydrate and Potassium Hexacyanoferrate (III) in dH20. Phosphate buffer solution ( $\mathrm{pH}$ 7.0) were prepared and stored at room temperature. Other chemicals were of analytical reagent grade and used as received. All aqueous solutions were prepared with deionized water and were carried out at room temperature condition of $25 \pm 0.1 \mathrm{oC}$.

\section{Apparatus and equipment}

The UV-visible spectrum of the assay was measured utilizing a PerkinElmer's UV-Vis spectrophotometer LAMBDA 35 (Perkin Elmer, USA) with $3.5 \mathrm{ml}$ quartz cells. The Ino lab $\mathrm{pH}$ meter was used and Mettler Toledo's Electronic mass balance will be used for weighing the reagents.

\section{Detection limit of allura red}

The detection limit of the assay was determined by observation of the color change characterize the reaction between Allura Red and Prussian blue (red to dark blue). The assay solution is conducted with the set of optimum conditions found during assay optimization. The assay solution consisted of diluted Allura Red mixed with Prussian blue at different concentrations. The Allura Red was diluted with different concentration range between 2 to $20 \mathrm{ppm}$.

\section{Analysis of real sample}

Candy, royal jelly, ice cream and soft drink were selected as detection samples in this work based on the published work with some modification [8]. These four samples were purchased from the local super market in Kota Kinabalu, Sabah, Malaysia. Firstly, $5.72 \mathrm{~g}$ candy, $10.07 \mathrm{~g}$ royal jelly and $30.05 \mathrm{~g}$ ice cream were respectively dissolved in $100 \mathrm{~mL}$ hot pure water $\left(\sim 45^{\circ} \mathrm{C}\right)$. Then, the each of the samples was filtered through a $0.45 \mu \mathrm{m}$ membrane filter to obtain solution without precipitation for subsequent use [9]. The soft drink sample was used directly without any pretreatment. The extracted samples were mixed with Prussian blue, and then analyzed according to the proposed colorimetric sensor procedure under UV-vis spectrophotometer.

\section{Result and Discussion}

\section{Optimization assay}

Effect of prussian blue: Simple kinetic principle for detection of Allura Red was being applied which known as indirect kinetic spectrophotometric method. The chromogenic reaction in direct kinetic method leads to reduction of Prussian blue in present of Allura Red. In this study, potassium hexacyanoferrate (III) was mixed with iron (iii) chloride hexahydrate to form Prussian blue and react with Allura Red shown in Figure 2. The possible kinetic principle for this experiment was involving the reduction of hexacyanoferrate (III) ion by Allura Red and resulting formation of an intermediate product. Then, the intermediate product reacted with iron (III) ion that producing highest absorbance at $497 \mathrm{~nm}$ in acidic medium. The spectral absorption of this kinetic system was influenced by the concentration of solution containing the iron (III) and hexacyanoferrate (III) ions, as well as $\mathrm{pH}$ of solution and temperature [10].

According to Tarasiewicz \& Karpinska [11], iron (III) and hexacyanoferrate (III) are oxidizing agents which oxidized promazine and thioridazine hydrochlorides to form oxidation products which are colored free radicals which are stable in acidic media Figure 2 .

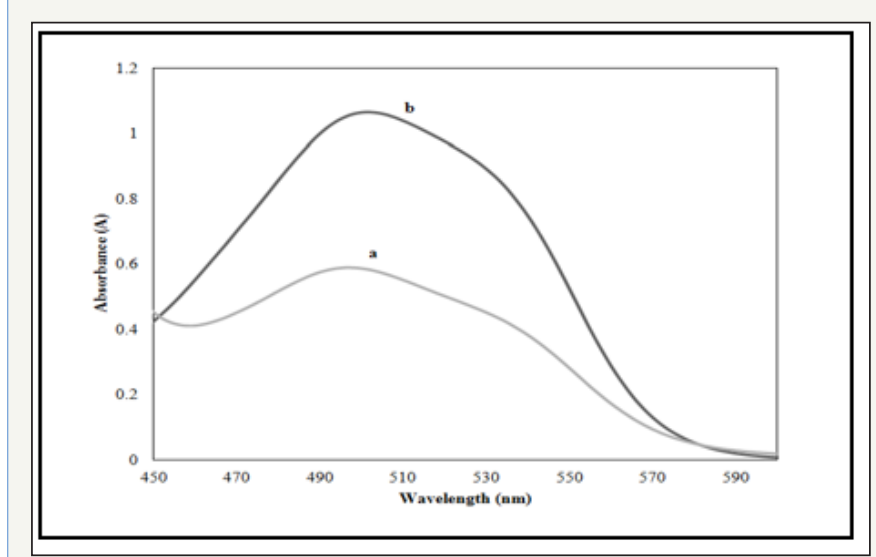

Figure 2: Absorption spectra of 20ppm of Allura Red AC (a) without and (b) with present of Prussian blue.

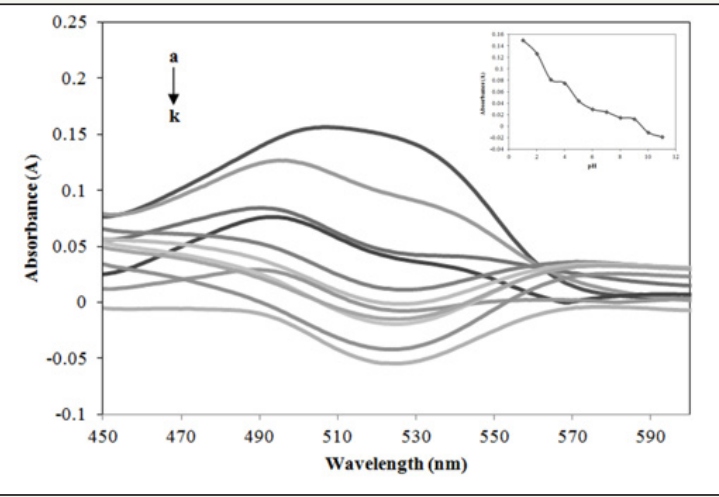

Figure 3: Absorption spectra of Allura Red with Prussian blue in different $\mathrm{pH}$ (pH a-k: 1, 2, 3, 4, 5, 6, 7, 8, 9, 10 and 11) at $497 \mathrm{~nm}$.

Effect of pH: The effect pH was studied between range $\mathrm{pH}$ 1-11 shown in Figure 3. The absorbance of interaction between Allura Red and Prussian blue directly proportional with $\mathrm{pH}$. The optimum $\mathrm{pH}$ was observed at $\mathrm{pH} 1$ with highest absorbance at $497 \mathrm{~nm}$. Present of hexacyanoferrate (III) has a small reduction potential, however; it is sensitive to the solvent and acidity in which by increasing amount of hydrochloric acid medium lead to an increase in redox potential [12]. 
Effect of temperature: Temperature plays an important factor that influence the reaction of Allura Red and Prussian blue. The effect of temperature was investigated with different temperature. Figure 4 shows the highest absorbance was at room temperature. When the temperature increase, absorbance value of Allura Red with Prussian blue was slowly decrease. Besides, it can be seen that the color of Allura Red disappeared faster during and slowly turns to dark blue. This is because the increase in reaction temperature may caused an increase in the rate of reaction [11]. The rate of reaction increase caused by hexacyanoferrate (III) in Prussian blue proceeds to second step of oxidation reaction which lead to disappeared of color solution. The disappeared of color of reaction solution directly influence the absorbance value. Therefore, the optimum temperature for the proposed colorimetric method was room temperature $\left(25 \pm 0.1^{\circ} \mathrm{C}\right)$.

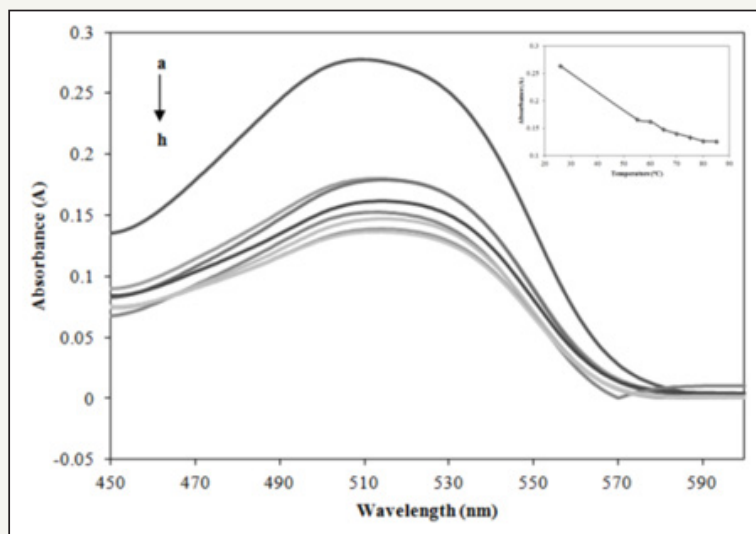

Figure 4: Absorption spectra of Allura Red with Prussian blue in different temperature (a-h: room temperature $(25 \pm 0.1 \mathrm{oC}), 55,60,65,70,75,80$, and $\left.85^{\circ} \mathrm{C}\right)$ at $497 \mathrm{~nm}$.

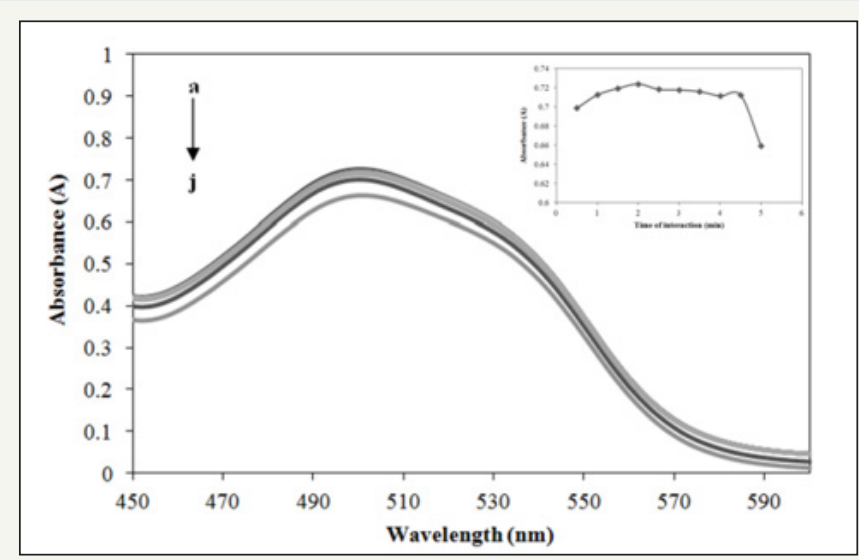

Figure 5: Absorption spectra of Allura Red with Prussian blue in different time interaction (a-j: 0.5, 1.0, 1.5, 2.0, 2.5, $3.0,3.5,4.0,4.5$, and 5.0 minutes) at $497 \mathrm{~nm}$.

Effect of time interaction: In this study, absorption spectra obtained varied in absorbance varied from 30 s to 5 min. Figure 5 shows the interaction time directly proportional to absorbance to reduction of Allura Red with Prussian blue. After $2 \mathrm{~min}$, the absorbance started to slowly decrease which indicated that the color obtained in the reaction is stabilized before drastically drop after $5 \mathrm{~min}$. Patil et al. (2009) reported that long standing time caused the product formed will undergo subsequent dis proposition. Hence, 2 min was selected as optimum time of interaction which approved that the method was feasible and powerful to develop a rapid colorimetric detection of Allura Red.

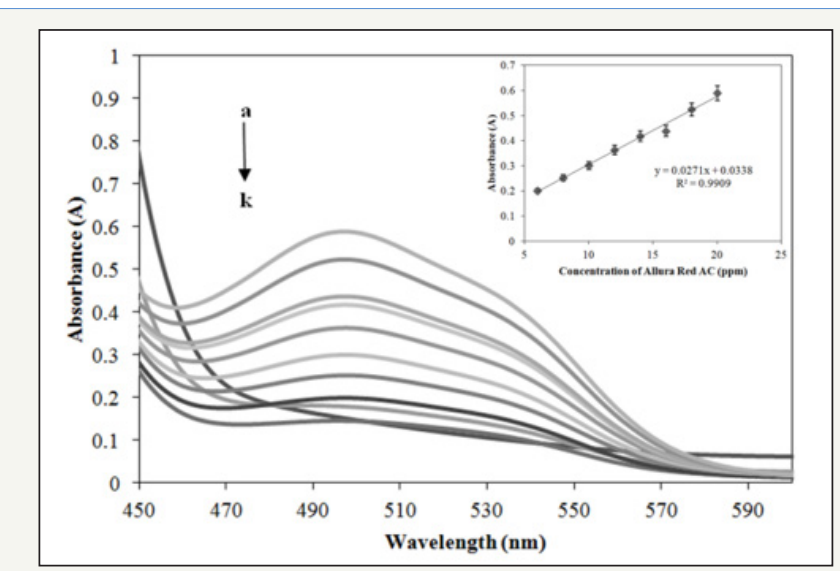

Figure 6: Absorption spectra of Allura Red with Prussian blue in different concentration (a-k: control, 2, 4, 6, 8, 10, $12,14,16,18$ and $20 \mathrm{ppm})$ at $49 \mathrm{~nm}$.

Detection limit of allura red: Figure 6 shows Allura Red with concentration of $20 \mathrm{ppm}$ give the highest peak and $2 \mathrm{ppm}$ lowest peak with absorbance of $0.58996 \mathrm{~A}$ and $0.08926 \mathrm{~A}$, respectively. Under optimum condition, the limit of detection (LOD) and limit of quantification (LOQ) were calculated $0.0244 \mathrm{ppm}$ and $0.0738 \mathrm{ppm}$, respectively. The linear regression equation for the calibration plot was calculated to be $y=0.0271 x+0.0338(R 2=0.9909)$, where $x$ is the concentration of Allura Red and $y$ is the oxidation current. A calibration curve was established to scrutinize the linearity of the technique. The precision of the method was obtained based on intraday variability that was determined by replicate analysis of the calibration standard in the same day.

Analysis of real samples: In order to validate and verify the applicability of the proposed colorimetric method, the detection of Allura Red in some food sample was studied. The colorimetric method was applied four different samples which are candy, royal jelly, ice cream and soft drink to investigate the applicability. The recovery rate was calculated to be 92.8 to $98.7 \%$, showing the accuracy of the developed method. The recovery rate of the proposed methods range showed good relative standard deviation (RSD) which was less than 1\% (Table 1). Paichamnan et al. (2014) reported the RSD less than $2 \%$ to be considered as sufficiently precise with acceptable of correlation coefficients.

Table 1: Recovery studies of food products.

\begin{tabular}{|c|c|c|}
\hline Samples & Recovery & RSD (\%) \\
\hline Candy & 92.8 & 0.46 \\
\hline Royal jelly & 94.8 & 0.58 \\
\hline Ice cream & 98.7 & 0.21 \\
\hline Soft drink & 96.9 & 0.43 \\
\hline
\end{tabular}




\section{Conclusion}

A simple, rapid and cost effective colorimetric assay developed based on Prussian blue as a redox for determination of Allura Red. The strong attraction between the reactive azo group of Allura Red and the negatively charged of Prussian blue change the color of mixture. The results showed from red to dark blue color changes which can be observed by the naked eye. The Allura Red LOD and LOQ were calculated $0.0244 \mathrm{ppm}$ and $0.0738 \mathrm{ppm}$, respectively with linear coefficient of 0.9909 . The detection limit obtained was below safety limit, indicating that the proposed method is applied successfully for the determination of Allura Red in food products and beverages.

\section{References}

1. Berzas NJJ, Rodrıguez FJ, Guiberteau CC, Villasenor LMJ, Contento SA (1998) Resolution of ternary mixtures of Tartrazine, Sunset yellow and Ponceau 4R by derivative spectrophotometric ratio spectrum-zero crossing method in commercial foods. Talanta 46(5): 933-942.

2. Curtis P (2002) The regulation of additives in the USA. In: Watson DH (Ed.), Food Chemical Safety. Additives. England: Woodhead Publishing Limited 2: 42-57.

3. Xing Y, Meng M, Xue H, Zhang T, Yin Y, et al. (2012) Development of a polyclonal antibody-based enzyme-linked immunosorbent assay (ELISA) for detection of Sunset Yellow FCF in food samples. Talanta 99: 125-131.

4. Ghorpade VM, Deshpande SS, Salunkhe DK (1995) Food Colorants. In: Maga JA, Tu AT (Eds.), Food Additive Toxicology, Marcel Dekker Inc, New York, USA, pp. 179-234.
5. Socaciu C (2008) Food colorants chemical and functional properties. Taylor \& Francis Group.

6. Sacide A, Suna T (2002) Determination of Tartrazine and Ponceau-4R in Various. Food samples by vierordt's method and ratio spectra firstorder derivative UV spectrophotometry. Journal of Food Composition and Analysis 15: 667-683.

7. Liangqia G, Jianhai Z, Jinmei W, Feng F Fu, Guonan C, et al. (2010) Visual detection of melamine in milk products by label-free gold nanoparticle. Talanta 82: 1654-1658

8. Sahraei R, Farmany A, Mortazavi SS (2013) A nano silver-based spectrophotometry method for sensitive determination of tartrazine in food samples. Food Chemistry 138(2-3): 1239-1242.

9. Shawish HM, Ghalwa NA, Saadeh SM, Harazeen HE (2012) Development of novel potentiometric sensors for determination of tartrazine dye concentration in foodstuff products. Food Chemistry 138(1): 126-132.

10. Ni Y, Wang Y, Kokot S (2009) Simultaneous kinetic spectrophotometric analysis of five food colorants with the aid of chemometrics, Talanta 78(2): 432-441.

11. Tarasiewicz HP, Karpinska J (2003) Analytical studies and application of reaction of promazine and thioridazine hydrochlorides with some oxidants, Acta Poloniac Pharmaccutica 60: 409-415.

12. Ariga GG, Mutalikdesai A, Jog D, Kirgi M, Nandibewoor ST, et al. (2014) Oxidation of captopril by hexacyanoferrate (III) in aqueous hydrochloric acid medium- A kinetic and mechanistic study, Indian Journal of Chemistry 53A: 159-166.
Creative Commons Attribution 4.0 International License

For possible submissions Click Here

\section{Submit Article}

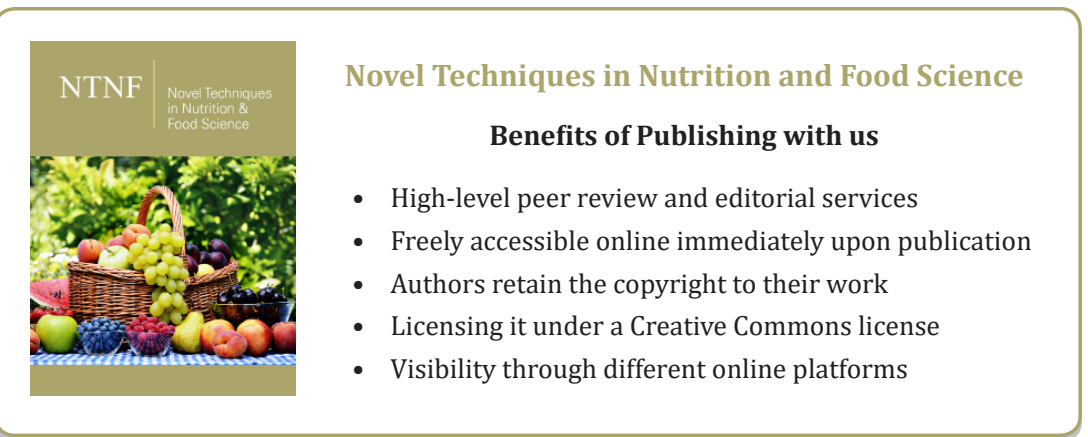

